\title{
Study of the behavior of vapor fraction in a turbopump inducer using an X-ray measurement technique
}

\author{
Walid Hassan · Stephane Barre $\cdot$ Samuel Legoupil
}

Received: 28 January 2013/Revised: 20 March 2014/Accepted: 9 April 2014/Published online: 26 April 2014

(C) Springer-Verlag Berlin Heidelberg 2014

\begin{abstract}
This work intended to study the behavior of the instantaneous vapor fraction in the turbopump inducer of a liquid propellant rocket engine. Experimentations held on an experimental pump test facility and cavitation was attained by reducing the inlet pressure in the machine while maintaining constant the inducer rotational speed. Measurements of vapor fraction through the rotating inducer were achieved by means of an X-ray-based system. The system exerted an industrial X-ray generator and 10 collimated scintillation detectors. Detectors were functioning in current mode thus permitting an acquisition at $5 \mathrm{kHz}$ for each detector. A reference X-ray detector situated between the X-ray generator and the machine permitted the treatment of X-ray beam energy fluctuations related to industrial generators. Acquisitions were performed in three axial positions on the inducer. For each measurement position, three cavitation sequences with different flow rate conditions $\left(Q / Q_{\mathrm{n}}=0.9\right.$, $1,1.1$, where $Q_{\mathrm{n}}$ is the nominal flow rate) were accomplished. Each cycle is performed by decreasing gradually the pressure while maintaining an imposed rotational speed of 4,000 rpm.
\end{abstract}

W. Hassan

Lebanese University, Beirut, Lebanon

W. Hassan ( $\square)$

IP and Science, SSR, MENA, Thomson Reuters,

Beirut, Lebanon

e-mail: walid.hassan@thomsonreuters.com

S. Barre

LEGI, GIT (Grenoble Institute of Technology)-CNRS,

Grenoble, France

e-mail: stephane.barre@inpg.fr

S. Legoupil

CEA (Commissariat a l'energie atomique)-LIST-Digiteo,

Saclay, France

e-mail: samuel.legoupil@cea.fr
Each test is constituted of 10 pressure points varying from 2.40 to 0.48 bars representing a complete cavitation sequence. X-ray acquisition was performed for each pressure point, and it was carried out for $10 \mathrm{~s}$ thus corresponding to 667 tours of the inducer. Vapor fraction was determined instantaneously thus showing the applicability and the precision of the method in such measurements despite of the geometry and rotation speed constraints. Consequently a quantitative and qualitative evaluation of the vapor fraction is presented. Results show that the vapor distribution is well related to cavitation development on the blades of the inducer for steady cavitation condition.

\section{List of symbols}

$\beta \quad$ Vapor fraction

$\sigma \quad$ The cavitation parameter or the similarity parameter for cavitation (Yue et al. 2001)

$I_{0}$ Calibration measurement when no liquid is in the machine

$I_{1} \quad$ Calibration measurement when the machine is full of water $(\beta=0)$

I Measurement with a vapor faction $\beta$ to be estimated

$I_{\text {no }}$ X-rays intensity received by the detector when no object is between the source and the detector

$I_{\text {ref }}$ A reference factor that indicates the level of the flux [energy, number of photons] of the X-ray beam

$\mu \quad$ Signifies the attenuation coefficient $\left(\mathrm{cm}^{-1}\right)$

$\rho \quad$ The density $\left(\mathrm{g} \mathrm{cm}^{-3}\right)$

$x$ Thickness $(\mathrm{cm})$

\section{Indices}

pw Housing walls

mi Inducer metal

W Water 
v Vapor

$d \quad$ Detector number

$\theta \quad$ Angular position of the inducer

\section{Introduction}

Conquering the space solicits industry to contrive launchers with more and more efficiency capable of transmitting more loads to space. Intending to procure in useful load, constructors are urged to run down the thickness of fuel tanks while reducing the drain pressure of the pumps. In order to thrust combustibles while pushing ahead, launchers engage high flow turbopumps. Being constrained by the size, the pump inducer, which constitutes the pump initial stage, should rotate at a very high speed to ensure a sufficient pressure gradient at constant flow rate in order to protect the main centrifugal pump stages from cavitation (Coulon 1999a, b). Indeed, the high speed of rotation of the turbopump and the low level of pressurization at the tank instigates the cavitation phenomenon (Lecoffre 1994). The cavitation manifests by the formation of vapor sheets on the suction side and at the tips of the inducer blades. Once this vapor is formed, it will move to the discharge side of the inducer and collapse where it is subject to a high positive pressure gradient. At first, vapor drop the inducer performance by the loss of mass flow (vapor density is lower than fuel density), when it reaches a critical amount in the inducer. A second effect is linked to the vapor structure instability which creates large pressure fluctuations in the inducer for some specific values of the vapor quantity. This phenomenon may lead to large flow fluctuations in the inducer and also in the whole engine feeding system. This situation may damage both the pump and the launcher (Shimizu et al. 2001).

Many research works were carried out attempting to develop methods (direct and indirect) to study the behavior of vapor pockets in the machine. Franc et al. (2001) studied the behavior of the vapor pockets by means of classical visualization of the machine. Image treatment and analysis methods were used to study and estimate the vapor volume of pocket in the machine, but it cannot offer a local measurement of the vapor fraction. Despite of its simplicity, this method demands special installations with non-opaque housing at the inducer level. Other more complex techniques of flow characterization such as PIV (Particle Induced Velocimetry) and LIF (Laser Induced Fluorescence) were tested by Chanteloup and Bölcs (2001). The difficulties related to these techniques are the diffraction of laser light by the bubbles and that these could not be applied for vapor fractions greater than $5 \%$ (Saarenrinne et al. 2004).

Recent non-experimental methods such as computational fluid dynamics (CFD) prediction of cavitation in fluids (Ebrahimi 2002) revealed interesting results, but they still need to be coupled with experimental measurements in order to be validated for further exploitation.

Returning to experimental methods, Han and Wesser (1993) presented a non-intrusive technique to estimate bubbles size and velocity in a two-phase flow (liquid + gas). Their approach was based on the Compton scattering of X-rays. Results obtained were significant and interesting as compared to numerical simulations and to laboratory experiments. However, this technique could not be applied to the current system due to its acquisition speed limitations $(30 \mathrm{~Hz})$, while the speed of rotation of the inducer in our application is $4,000 \mathrm{rpm}(66 \mathrm{~Hz} \times 4$ blades $=266 \mathrm{~Hz}$ for each blade).

Stutz et al. (2002) and Stutz and Legoupil (2003) performed experiments on a Venturi channel designed to reproduce similar cavitation structures to that observed on the blades of an inducer. They used an ionizing-radiationbased system in order to study the distribution and the behavior of vapor fraction through a two-phase flow in the cavitating section downstream the throat of Venturi. Their system exerted an X-ray generator and a set of scintillation detectors along the flow channel. The method is presented in details in the third part of this paper.

Accordingly this method allowed to describe the vapor fraction evolution and to determine the vapor fraction with a mean relative error of order of $3 \%$. However, their results agreed well with those found by comparative measurements obtained by an intrusive technique based on optical probe measurements inside the cavity on static condition on the suction wall. This comparison approves the originality of the X-ray method to obtain instantaneous distribution of the vapor fraction in the whole cavity and using a one-shot technique. The same geometry was subscaled so that it could be tested in a Synchrotron device. Results are presented in Vabre et al. (2009).

Similar works were carried on by Coutier-Delgosha et al. (2003) based on the same method. They presented a numerical and an experimental investigation of the internal structure and the dynamics of a 2D sheet cavitation on the suction side of a $2 \mathrm{D}$ foil section. Their experiments were conducted in a cavitation tunnel. Cavitation conditions ranging from steady sheet cavitation to unsteady cloud cavitation were obtained by varying the foil incidence and the cavitation number. Using a new endoscopic technique, coupled with X-ray attenuation measurements, the twophase morphology and the void fraction within the sheet cavitation were presented. The results are compared to numerical results obtained by solving the Navier-Stokes equations coupled to a model of a single fluid with variable-specific mass to simulate the cavitation phenomenon. The comparisons show good agreement of: (a) the void fraction distribution, (b) the frequency of the cavity 
oscillations, and (c) the shape of the sheet and the detached cloud cavity.

During the recent years, the experimental study of cavitating flows using X-ray absorption techniques gained a lot of popularity. For example, it was extensively used in the study of high-pressure fuel sprays issuing from diesel engines injectors. Work from Kastengren et al. (2007a, b), $\mathrm{Yu}$ et al. (2001), Cheong et al. (2004) and Powel et al. (2003) investigated the spray characteristics of single-hole research nozzles injecting into ambient pressures. More recently, Leick et al. (2007) used a multi-hole single fluid injection system to investigate the corresponding spray using X-ray radiography. Ramirez et al. (2009) use also $\mathrm{X}$-ray radiography techniques to explore the near-nozzle region of a production multi-hole injection in order to obtain quantitative information about high-pressure nonevaporating sprays.

More sophisticated techniques, using X-ray computed tomography (CT), were also used to obtain a 3D reconstruction of the void ratio field. Giannandakis et al. (2008) use it in a high-pressure fuel spray from a diesel engine injection system. Bauer et al. (2012) performed a tomographic reconstruction in a cavitating pipe flow. The work of Mäkiharju et al. (2013) can also be cited in which a realtime 2D visualization of a two-phase flow downstream of a ventilated cavity was performed. The synthesis review done by Heindel (2011) about the use of X-ray systems in multiphase flows can also be mentioned.

Certainly the efficiency and the robustness of the method endorse its application in exploring more complex systems such as 3D designs of Ariane inducers. Afterward the main concept of this study is to adapt the later described technique to study experimentally and instantaneously the dynamic behavior of vapor fraction within the machine, taking into account the environment and the complexity of the experimental system. This will be achieved through the production of instantaneous tomographic images of the vapor fraction in the measurement section of the machine. See ref. Hassan et al. (2008) for an accurate description of the used measurement technique in the context of the present work.

\section{Experimental model}

Experiments were performed on the water test bench of the Centre de Recherche et d'Essais de Machines Hydrauliques de Grenoble [CREMHyG]. The bench is equipped with a special Aluminum inducer designed by Snecma, the company in charge of the Vulcain engine turbopump (ARIANE $\mathrm{V}$ rocket). A description of this experimental device can be found in Franc et al. (2001) and De Bernardi (1996). This is a close loop in which the inducer is entrained by an electrical motor. A large free surface tank is mounted downstream the inducer. This device permits the loop pressure management independently from the flow rate. In the present study, we will use cold water $\left(\approx 20^{\circ} \mathrm{C}\right)$ as the working fluid. The cavitation level of the flow is measured by the number $\sigma$, which is here defined as follows:

$\sigma=\frac{P_{\mathrm{am}}-P_{v}}{\rho R^{2} \omega^{2}}$

where $P_{\mathrm{am}}$ is the reference pressure just upstream of the inducer. $P_{\mathrm{v}}$ is the water vapor pressure. $\rho$ is the liquid water density. $R$ is a reference radius for the inducer. $\omega$ is the inducer angular speed.

It is possible to change the $\sigma$ number without changing both the flow rate and the inducer rotational speed. Figure 1 shows a schematic view of the hydraulic loop. The classical test procedure consists in gradually decreasing the $\sigma$ number for a given flow rate and rotational speed. $\mathrm{X}$-ray detector signals are then acquired for each $\sigma$ in order to compute the vapor volume in the inducer. In the present experiment, we test, for example, a $\sigma$ range from $\sigma=0.013$ (no cavitation) to $\sigma=0.0016$ (maximum cavitation) in the nominal $\left(Q / Q_{\mathrm{n}}=1\right)$ testing case.

Cavitation is then produced by reducing the inlet pressure of the pump, while maintaining the inducer rotation speed at 4,000 rpm. The cyclo-stability of cavitation structures is required in order to perform image reconstruction later. A position sensor situated at the housing of the machine provides the angular position of the inducer. This sensor provides a signal between 0 and $10 \mathrm{~V}$ corresponding to angular positions between 0 and $360^{\circ}$. Cavitation measurements were performed in three axial positions at the machine, with a section thickness of $20 \mathrm{~mm}$ for each axial position [see Hassan et al. (2008), Hassan (2005) for details]. However, most of the important phenomenon arises in the first axial section at the inducer entrance. Consequently, the present study will be focused on this area. Figure 2 shows a sketch of the inducer's upper view in which the X-ray source, the $\mathrm{X}$-ray path (measurement area) and the detectors are displayed and located in order to describe the measurement area studied in the present paper.

Measurements were achieved by immobilizing the source-detector measurement system while rotating the inducer. Projections were acquired by 10 detectors for a total of 75 angles of incidence. Figure 3 displays a front view of the inducer both with $\mathrm{X}$-ray path and detector rack.

Measurements could not be acquired in the center of the machine due to the presence of the mounting axis holding the inducer, which constitutes $35 \mathrm{~mm}$ of iron. This quantity of iron is capable of absorbing all incident X-ray photons in the energy range in which we are working.

The X-ray absorption technique is used to perform integral measurements of the vapor volume in the inducer. 

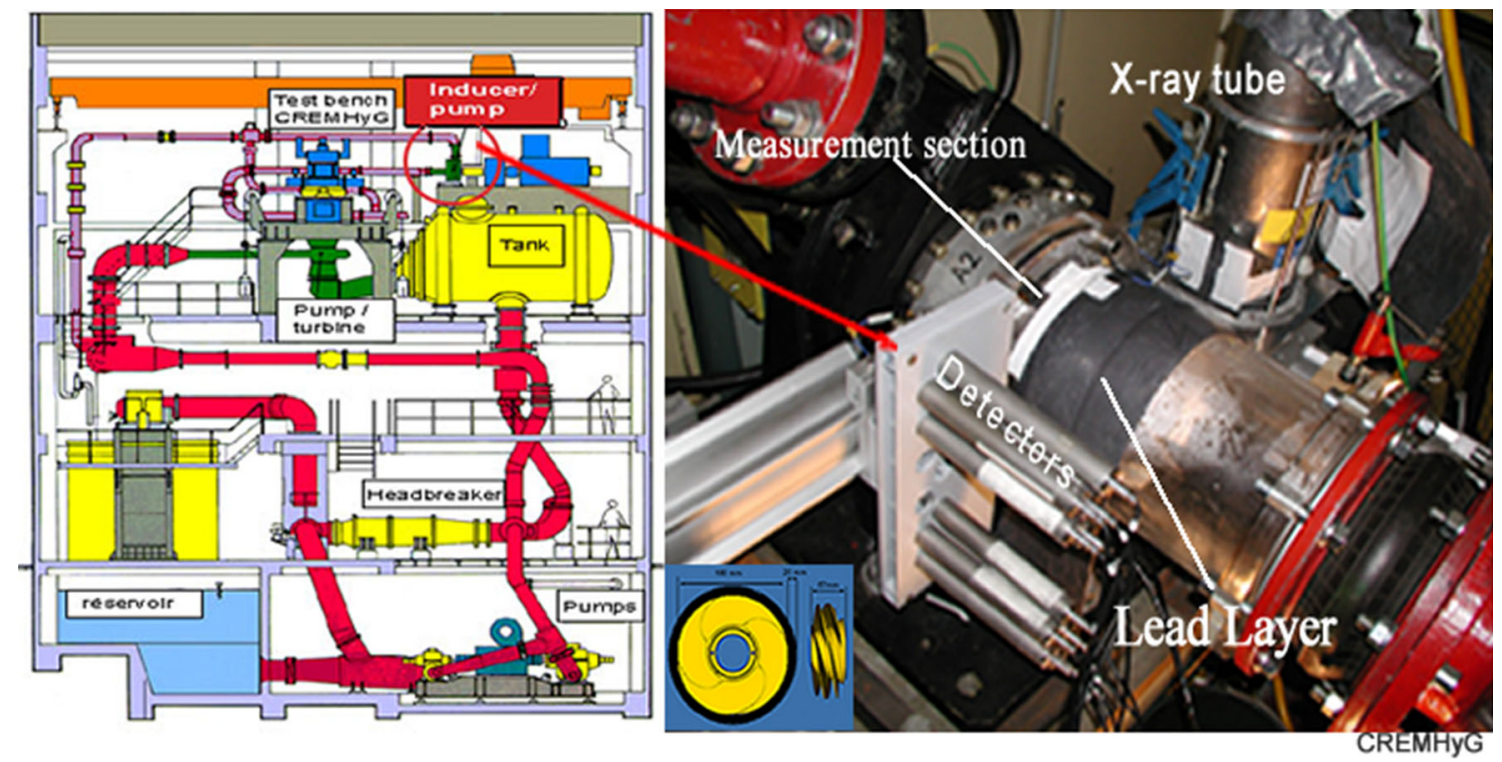

Fig. 1 Sketch of the experimental hydraulic loop

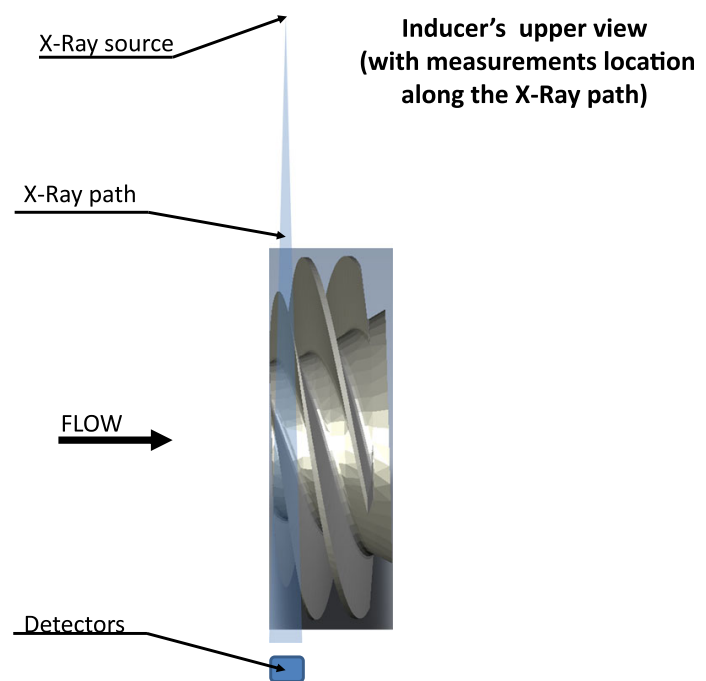

Fig. 2 Inducer's schematic upper view with X-ray path and detectors localized

We define the vapor fraction, $\beta$, as the ratio of the volume of vapor to the total volume of measurement:

$\beta=\frac{\text { Volume of vapor }(t)}{\text { Total measurement volume }}=1-\frac{\ln \left[\frac{I_{0}(\theta)}{I(\theta)}\right]}{\ln \left[\frac{I_{0}(\theta)}{I_{1}(\theta)}\right]}$

where $I(\theta)$ is the actual detector current value for a given inducer position $(\theta) . I_{0}(\theta)$ is the corresponding current value obtained with an empty system (full of air, $\beta=1$ ). $I_{1}(\theta)$ is the corresponding current value with the system full of water $(\beta=0)$. $I_{0}(\theta)$ and $I_{1}(\theta)$ are obtained from a preliminary calibration in which data are collected for each angle $\theta$ with, respectively, the empty $\left(I_{0}\right)$ and full of water $\left(I_{1}\right)$ system.

A lot of technical information concerning the measurement method can be found in Hassan et al. (2008) and Hassan (2005).

A Philips M160 X-ray generator and $11 \mathrm{NaI}$ scintillation detectors functioning in current mode were employed to perform integral measurements. The $\mathrm{X}$-ray tube highvoltage supply was fixed at $80 \mathrm{kV}, 30 \mathrm{~mA}$ for $I$ and $I_{1}$ measurements while $I_{0}$ is performed at $80 \mathrm{kV}, 5 \mathrm{~mA}$ to avoid saturating the detectors. Detector positions were selected based on the opening angle of the beam from the $\mathrm{X}$-ray tube. Unfortunately, due to the presence of support equipment for the pump, the same detector source spacing could not be used for all of the detectors [see Hassan (2005) for details].

Technical parameters of the system (high voltage, current, detection area, etc.) were optimized to ensure a good signal-to-noise ratio and thus to reduce the measurement error. Simulation codes such as VXI (Freud et al. 2006) and Macalu 7 (Tola 1996) were used for this purpose. Practically the measurement error is inversely proportional to X-ray intensity (defined by the tube current) and the measurement time. Because the high rotational speeds limit the measurement time, we used the maximum tube current at the lowest acceptable tube high voltage to maximize the contrast.

Signals issuing from $\mathrm{X}$-ray detectors as well as signals from the position sensor, and pressure sensors situated at the housing of the machine were acquired simultaneously. The acquisition was performed with a National Instruments 
Fig. 3 Employed measurement system [inducer's front view; from Ref. (Hassan et al. 2008)]

\section{Detectors rack: \\ D1 (top) to D10 (under)}

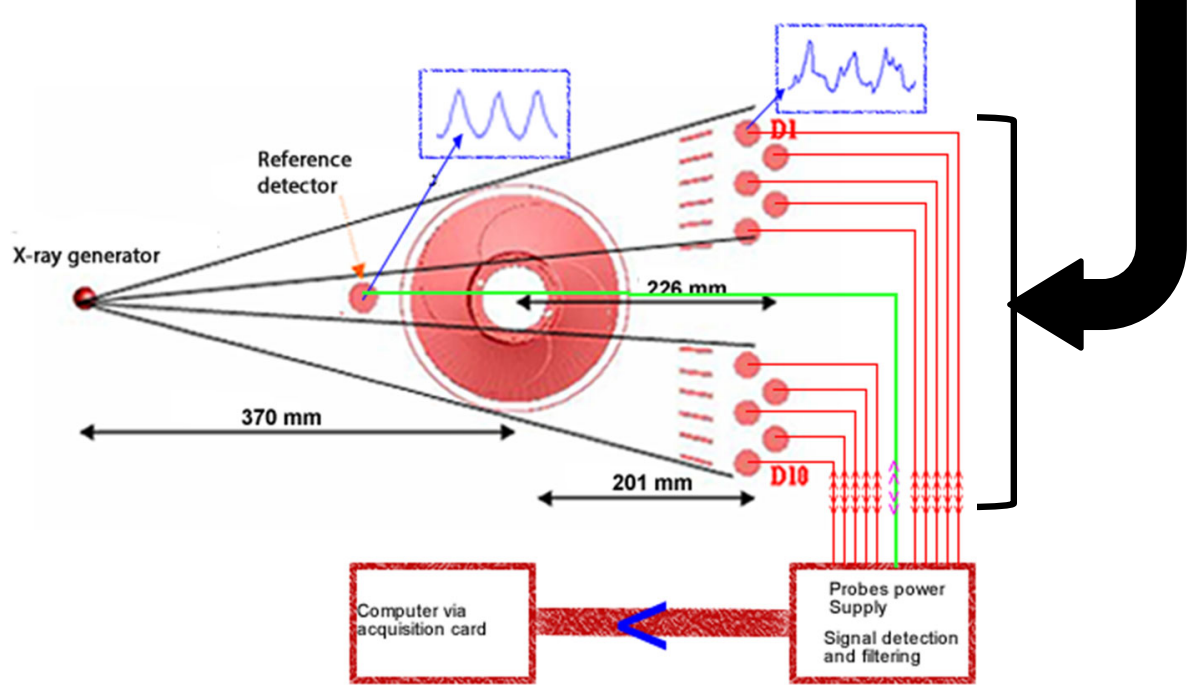

[NI] acquisition card (PCI 6033) using Labview. The acquisition frequency is $5,000 \mathrm{~Hz}$ at each detector, thus permitting to acquire 75 projections during one complete rotation of the inducer. This reflects a measurement time in the order of $200 \mu$ s per projection. The presence of a reference detector situated between the X-ray tube and the machine is shown on Fig. 3. The purpose of this detector is to monitor the X-ray beam, and the acquired signal is used for treating instabilities in the X-ray beam. These fluctuations are related to the high-voltage generator of the X-ray tube. The procedure to eliminate the fluctuations has been previously described (see Hassan et al. 2005a, b, 2008). The main idea is to perform a double calibration in order to determine the vapor fraction: one for the angular position $\theta$, and another for the variations of energy and flux provided by the reference detector. Therefore, the void fraction measured at a time $t$, in an angular position $\theta$, by a detector $d$ is given by:

$\beta^{d}(\theta, t)=1-\frac{\ln \left(\frac{I_{0}^{d}\left(\theta, I_{\text {ref }}, t\right)}{I^{d}\left(\theta, I_{\text {ref }}, t\right)}\right)}{\ln \left(\frac{I_{0}^{d}\left(\theta, I_{\text {ref }}, t\right)}{I_{1}^{d}\left(\theta, I_{\text {ref }}, t\right)}\right)}$

\section{Results and discussion}

\subsection{Statistical analysis for different sensors}

Data acquisition was performed during $10 \mathrm{~s}$ for each experimental pressure setting. This corresponds to 50,000 samples for each detector. A statistical analysis is performed on the signals recorded by the 10 detectors. In what follows the mean, standard deviation and their ratio are studied. Firstly, the statistical convergence of the mean and the standard deviation is analyzed for certain typical cases of flow (Fig. 4a, b).

The Fig. 4a shows the evolution of the ratio of the mean void fraction on a certain number of samples $N$ divided by the value obtained on the total acquisition time $(50,000$ samples). The results presented in the figure (given as a representative example) are measured in the case of a nominal flow $\left(Q / Q_{\mathrm{n}}=1\right)$ and at the extremity points of a cavitation cycle. We use the signal issuing from the detector (D3), i.e., a sensor situated near the fixing armature of the machine (see Fig. 3). The cavitation parameter $(\sigma)$ for the two chosen points is, respectively, 0.0456 and 0.0056 . The first corresponds to high-pressure conditions at the beginning of the cavitation cycle while the second corresponds to very low pressure at the end of the cycle.

From these results, we notice that the mean converges more rapidly when cavitation is low, i.e., at high pressure, than at high cavitation. However, admitting a $3 \%$ uncertainty interval, the mean could be considered converged after only 5,000 samples in the two cases. This value corresponds to $1 \mathrm{~s}$ of acquisition what corresponds to 66 rotations of the inducer.

The Fig. $4 \mathrm{~b}$ presents the convergence of the standard deviation of the fluctuations of void fraction fluctuations obtained for the same case previously discussed (Fig. 4a). Here also, admitting a $3 \%$ uncertainty interval, we could consider that after 10,000 samples ( $2 \mathrm{~s}$ of acquisition, 132 rotations of the impeller), the standard deviation of the void fraction is converged. 
(a)

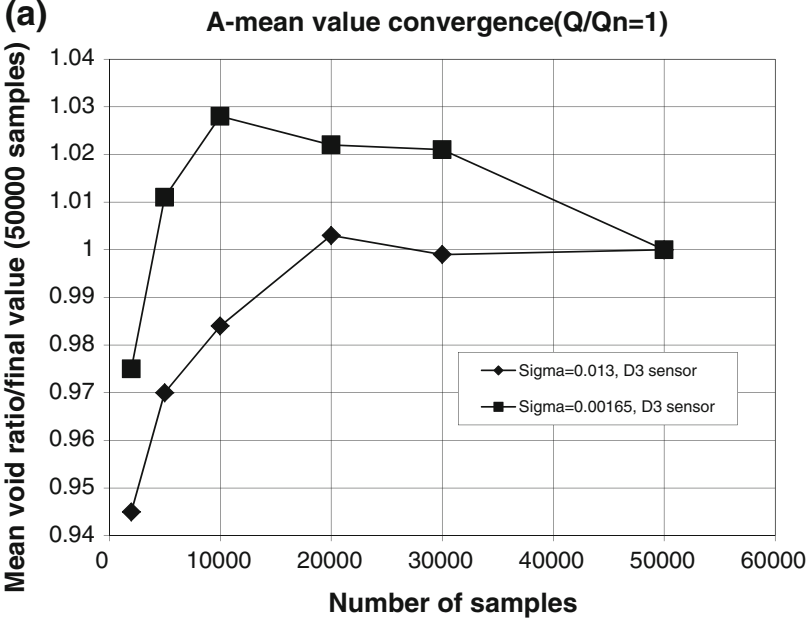

(b) B-RMS value convergence $(Q / Q n=1)$

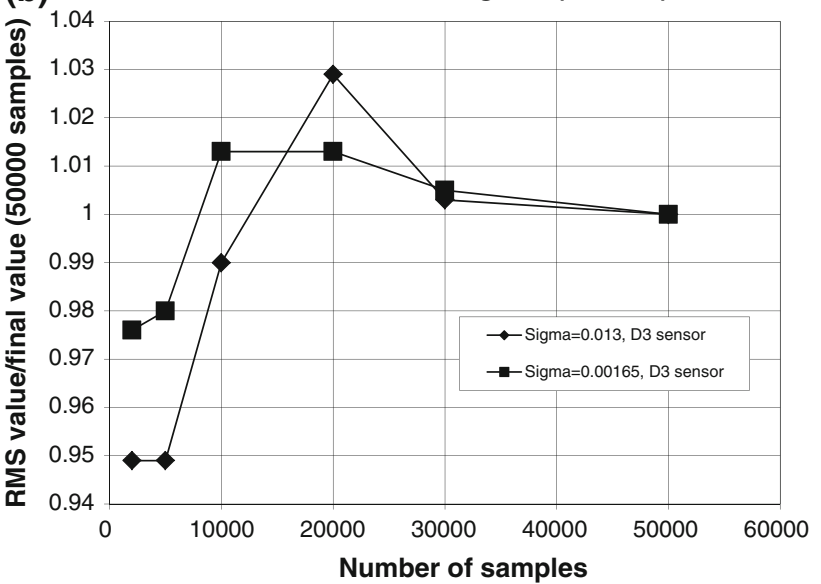

Fig. 4 a Convergence of the mean of certain number of samples weighted to the mean on the total acquisition time (50,000 samples). b Convergence of the standard deviation obtained on a number of samples $N$ weighted to the standard deviation on the total acquisition time $(50,000$ samples $)$

These two results permit us to consider our data as converged if we use the 50,000 samples of each acquisition file. Furthermore, these results are useful in order to define the minimal threshold for the number of samples to be considered when analyzing the phase averages.

The mean value of the void fraction (calculated on 50,000 samples of each acquisition) as seen by each detector is presented in the Fig. 5. At this stage, the reader is informed that, all the following presented results in term of void ratio are divided by a constant value for confidentiality reasons.

The curves displayed on the Fig. 5 correspond to different cavitation numbers $(\sigma)$ for a subnominal flow $\left(Q / Q_{\mathrm{n}}=0.9\right)$. We notice that the void fraction (in average) is greater for small values of $\sigma$. In addition the spatial repartition of this void fraction illustrates the lofty cavitation seen at the blades extremities (detectors 1, 2, 9 and
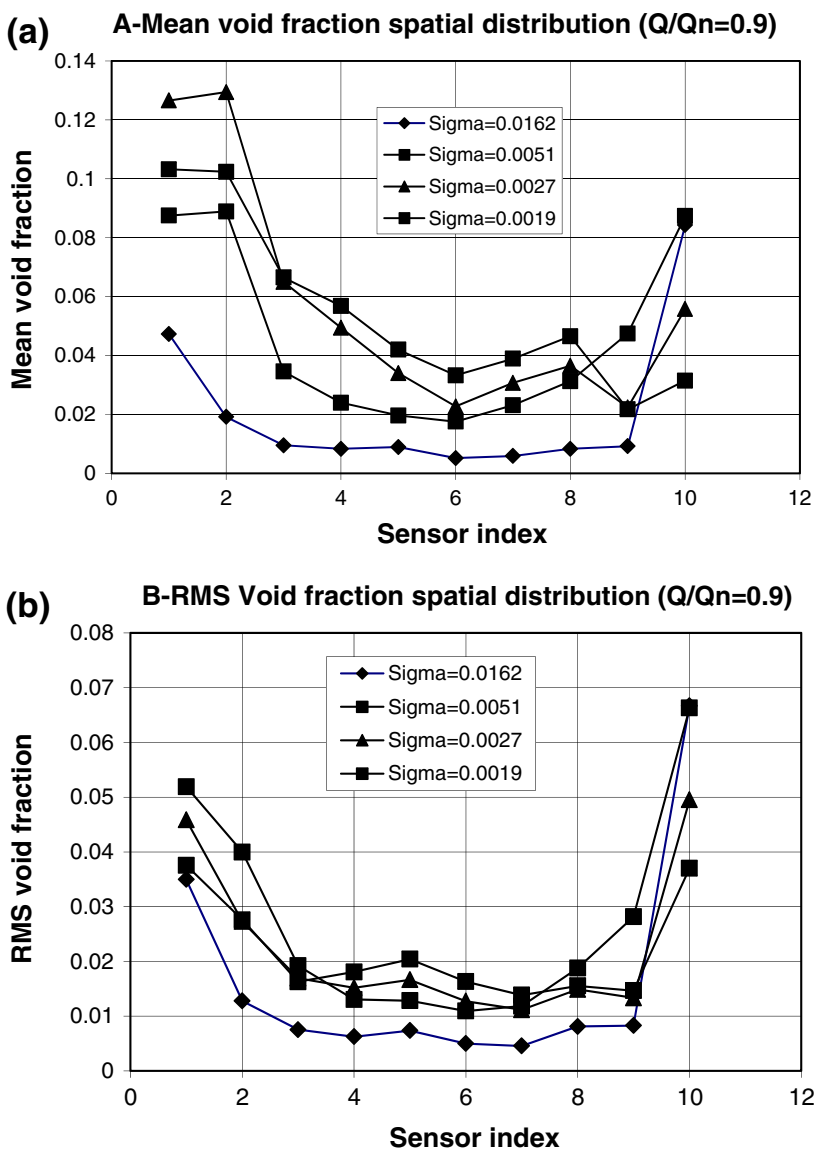

Fig. 5 a Global mean void fraction for $Q / Q_{n}=0.9$. b Standard deviation of the void fraction for $Q / Q_{n}=0.9$

10), by the beginning of the cavitation cycle. In fact even for high $\sigma$ values, we have a non-negligible mean void fraction at the blade extremities while near the center the values are close to zero.

When $\sigma$ decreases, the mean void fraction increases anywhere in the machine. We notice particularly, near the center of the impeller, that the mean void fraction attains huge values in some zones. This illustrates the presence of cavitation pockets attached to the blades. Simultaneously, the void fraction at the extremities of blades (tip vortex cavitation) may reach their maximum value just before the end of the cycle. However, it stabilizes at a lower value at the end of the cycle. At this moment the head drop and the tip vortices intensity decreases and thus the associated void fraction also. We should note that in the central zones, the void fraction continue to increase till the end of the cycle showing that the sheets attached to the blades increase continuously although the head drop.

The void fraction values obtained-even though they are spatially averaged along the $\mathrm{X}$-ray measurement lineshow that the sheets attached to the blades are not exclusively constituted of vapor. Therefore, we should take into 


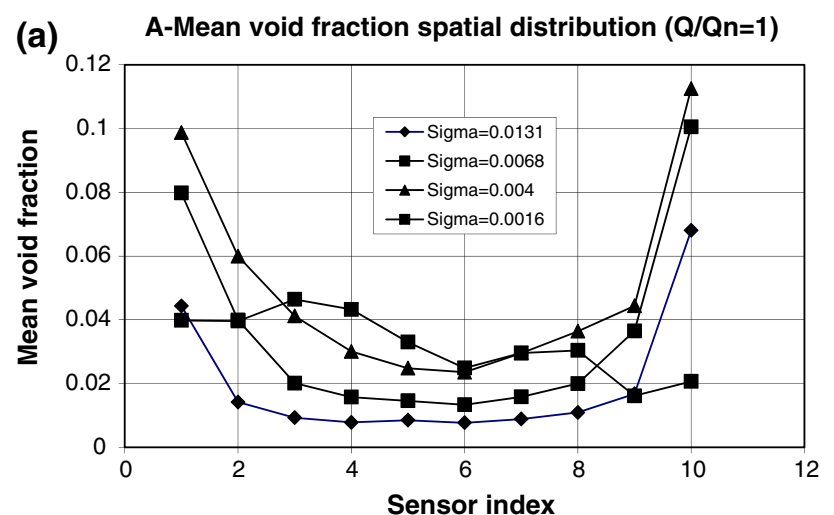

(b) B-RMS void fraction spatial distribution $(Q / Q n=1)$

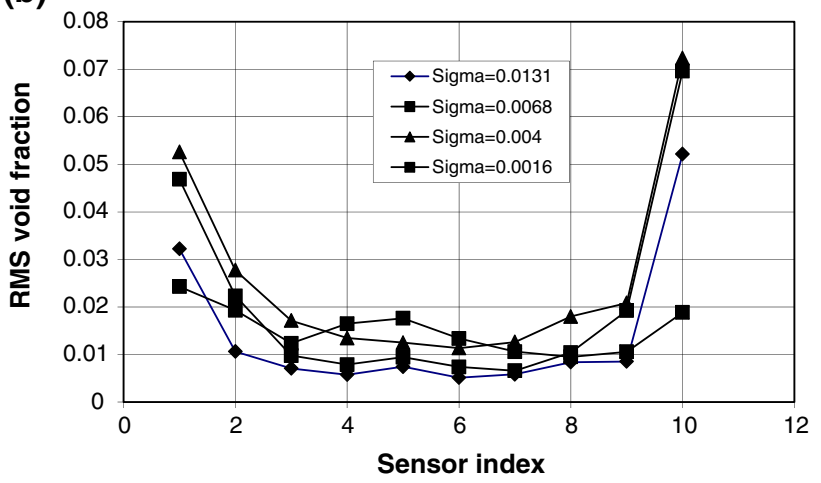

Fig. 6 a Global mean void fraction for $Q / Q_{n}=1.0$. b Standard deviation of the void fraction for $Q / Q_{n}=1.0$

account some effects related to the non-equilibrated thermo dynamical change of phase in order to explain the composition of these cavitation sheets.

In the same manner, the Figs. 6a and 7a show the same results for nominal flows $Q / Q_{n}=1$ and $Q / Q_{n}=1.1$.

Qualitatively, we could deduce the same conclusions as for the subnominal flow $Q / Q_{n}=0.9$. We observe the same global tendencies provided that the maximal values of void fraction are lower.

The Figs. 5b, 6b, 7b describe the values of the standard deviation of the fluctuations of the void fraction. Again, from a qualitative point of view, their behavior is similar to that of the mean void fraction. We notice always that maximum values are found at the blade extremities. The fluctuation level drops on these extremities before the end of the cavitation cycle due to the head drop of the machine. In addition, the attached sheets show more fluctuations in the void fraction as $\sigma$ decreases. The maximum values obtained are very close as considering the nominal flows $Q / Q_{\mathrm{n}}=0.9$ and $Q / Q_{\mathrm{n}}=1.0$ while for $Q / Q_{\mathrm{n}}=1.1$ a more less (approximately the half) fluctuation rate is found.

In general, we can remark a certain dissymmetry on the Figs. 5 and 7 on the extremity detectors ( 1 and 2 as well as 9 and 10). This is particularly visible for the measurements with

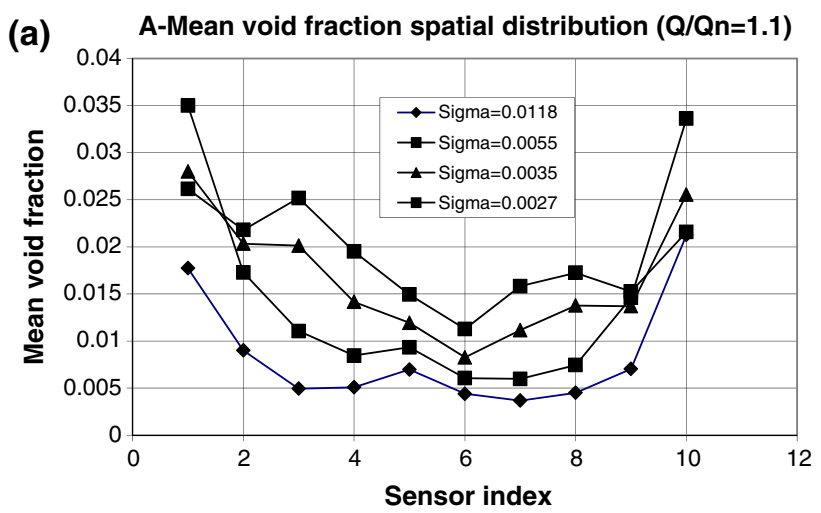

(b) B-RMS void fraction spatial distribution $(\mathrm{Q} / \mathrm{Qn}=1.1)$

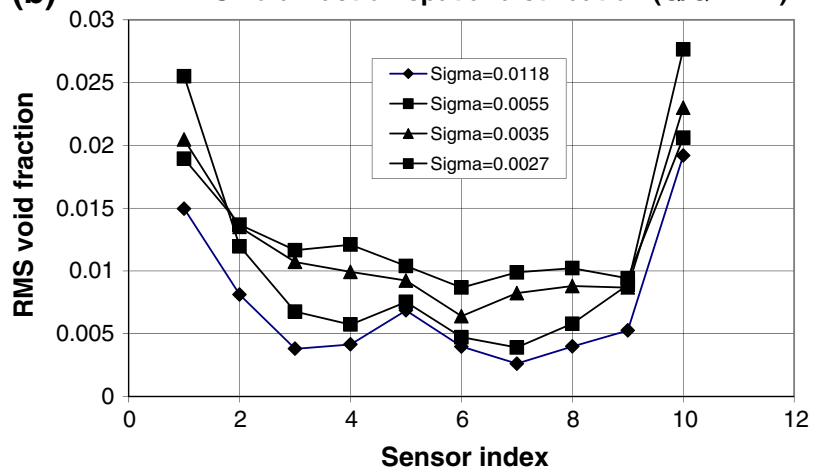

Fig. 7 a Global mean void fraction for $Q / Q_{n}=1.1$. b Standard deviation of the void fraction for $Q / Q_{n}=1.1$

low $\sigma$, where at the extremity of the machine (9 and 10) the void fraction fluctuates more than its symmetric detector. This dissymmetry is induced by the particular geometry of the impeller that does not offer the same field of view for detectors positioned symmetrically with respect to axis.

\subsection{Global statistical analysis on the machine}

In previous paragraphs, we presented the spatial repartition of mean values and the temporal fluctuations of the void fraction. Aiming to perform an analysis more focused on the behavior of the "system" of the cavitating inducer, we are interested now in the measured global values of the void fraction. In order to attain this goal, we will proceed in three different manners:

- At first by averaging point by point the values in the signals issuing from the 10 detectors. The obtained signal gives us an idea of the global void fraction in a considered zone of the machine. This averaging operation is achieved by giving to each detector a weight (coefficient) corresponding to distance covered by the X-ray beam in the flow. However, this represents a simpler way to take into account the quantity of fluid present in the field of view of each detector. 
- The second manner is to determine the average only on the six $(3+3)$ central detectors. This permits to take into account the influence of cavitation sheets attached on the blades. This technique permits us to have an idea-less global than the first-allowing a quantitative description of the effect of these sheets and to relate the fluctuations of the void fraction in the central zone to the unstable behavior of the flow for some particular $\sigma$ values which characterize cavitation inducer instability.

- The third technique is to achieve the average on the four $(2+2)$ lateral detectors. This permits to study the influence of tip vortices.

The Fig. 8 presents the evolutions of the mean void fraction, the standard deviation of the fluctuations of the void fraction and the ratio of these two quantities, respectively. The data shown in this figure are determined via the first technique that is to calculate the global mean (10 detectors). The evolutions are shown as a function of the cavitation parameter $\sigma$ for the three different flows tested.

We perceive on the Fig. 8a that the mean void fraction attain higher values for the cases $Q / Q_{n}=0.9$ and $Q / Q_{n}=1.0$ than that for $Q / Q_{n}=1.1$. In the case where $Q / Q_{n}=0.9$, the growth of the void fraction takes place rapidly in the zone where $\sigma$ is between 0.0040 and 0.008 $(0.004<\sigma<0.008)$. However, the void fraction drops for the very low values of $\sigma$. Therefore, in this case, where the incidence of flow with respect to the blade is high $\left(Q / Q_{n}=0.9\right)$, a very rapid growth of cavitation sheets takes place, leading to a head drop that decreases the void fraction at the end of the cavitation cycle.

Now taking into consideration the fluctuations of the void fraction and more particularly their relative values (Fig. 8c), we observe that the three nominal flows have a qualitatively comparable behavior provided that the relative level of fluctuations decreases with $\sigma$. Matching these results with what shown in the Fig. 6 b, in which we could notice that the level of fluctuations increase when $\sigma$ decreases, we conclude that the growth of the global void fraction is faster than the associated fluctuations. Yet, we are not able to distinguish the relative influence of different zones of the machine in this global cavitation behavior. However, to achieve this, we are going to study the other two averaging methods.

Figures 9a and 10a show the evolution of the mean void fraction as a function of $\sigma$ for the three nominal flows studied, taking into account the central detectors (Fig. 9) and the lateral (Fig. 10) separately.

The difference in the behavior is clearly apparent. The central detectors assess a void fraction that increases continuously as $\sigma$ decreases. This illustrates well the phenomenon of growth of sheets attached to the blades. On the

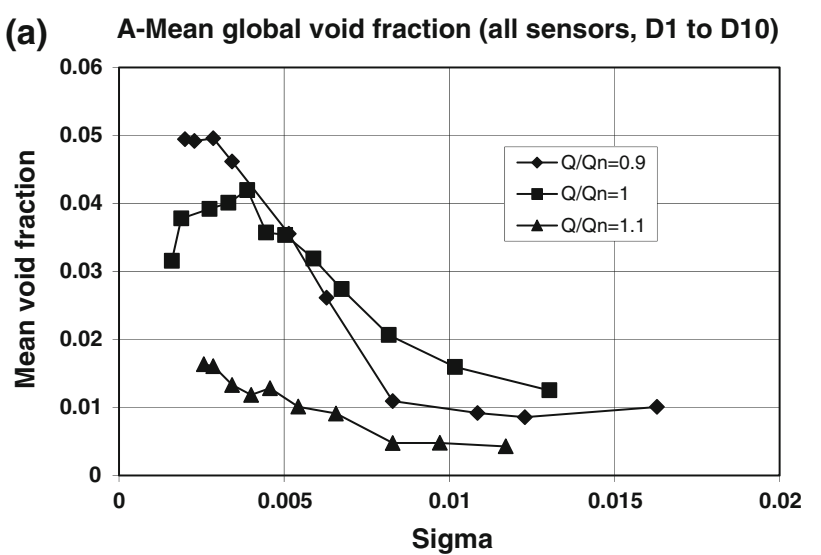

(b) B-RMS global void fraction (all sensors, D1 to D10)

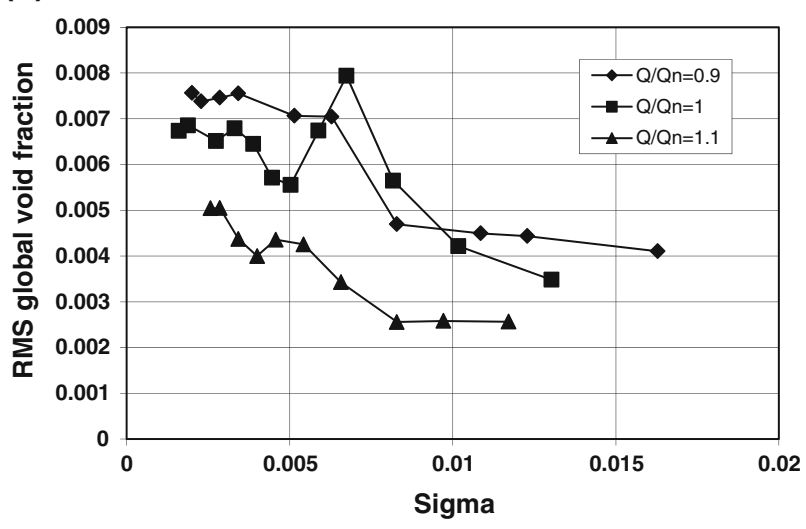

(c) C-Global RMS/Mean void fraction (all sensors, D1 to D10)

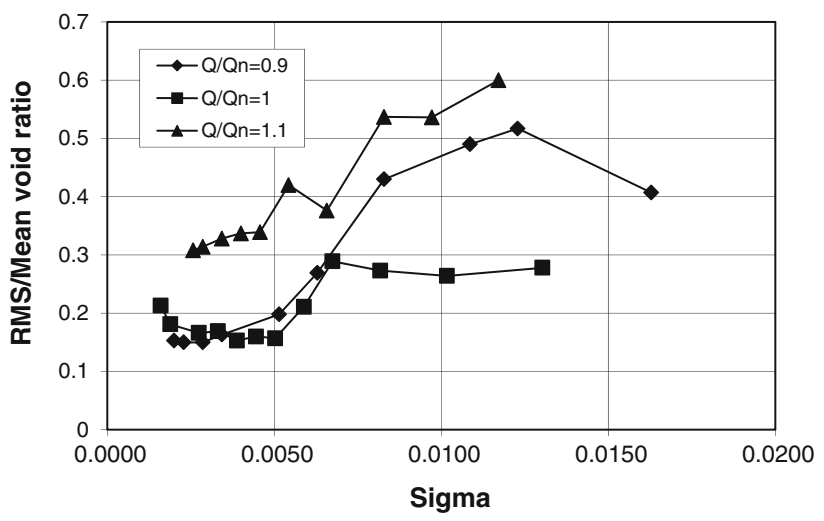

Fig. 8 a Mean void fraction for different $\sigma$ for the three tested flow rate values. $\mathbf{b}$ The standard deviation of the void fraction. $\mathbf{c}$ The ratio of the standard deviation to the mean

other hand, for the lateral (extremity) detectors, we notice an increase in the void fraction at the beginning followed by a drop in the values related to the drop in the performance of the machine and to the tip vortices that are situated in an intense pressure gradient zone.

The void fraction growth is fast for $Q / Q_{n}=0.9$, while it is slower for $Q / Q_{n}=1.0$ and it is very slow for $Q / Q_{n}=1.1$. In fact, the more the flow rate is low and the 


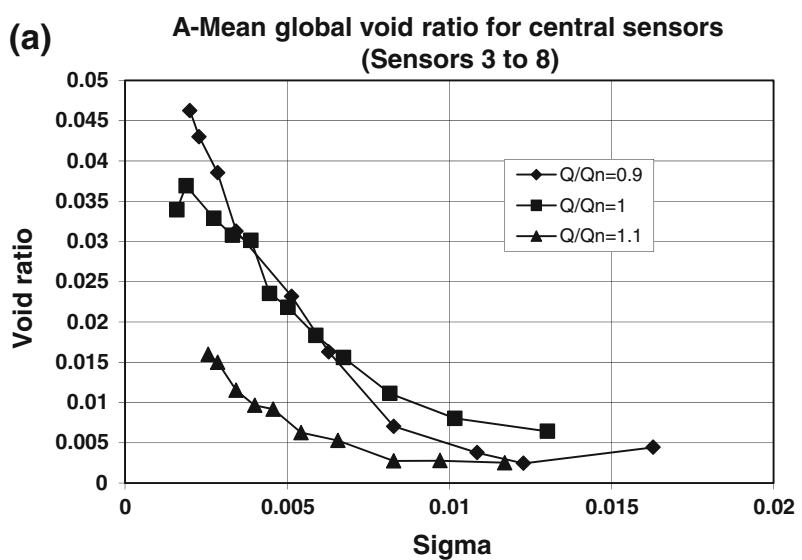

(b) B-RMS global void ratio value for central sensors

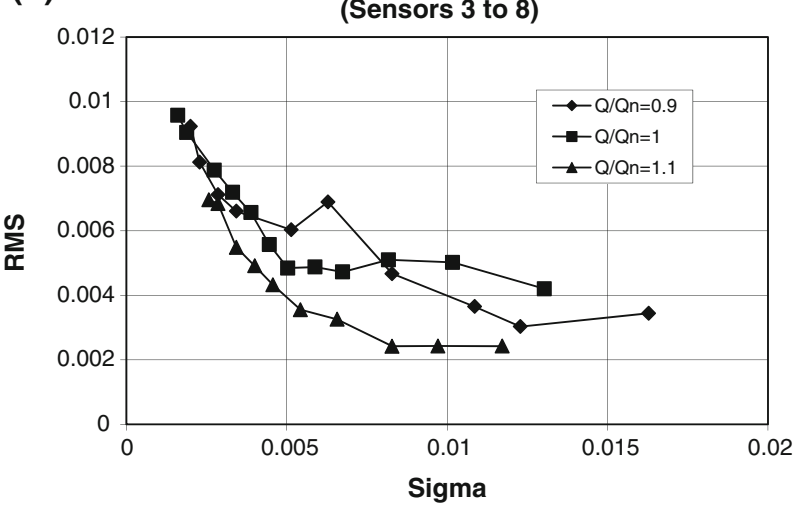

(c) C-Relative RMS global void ratio value for central sensors

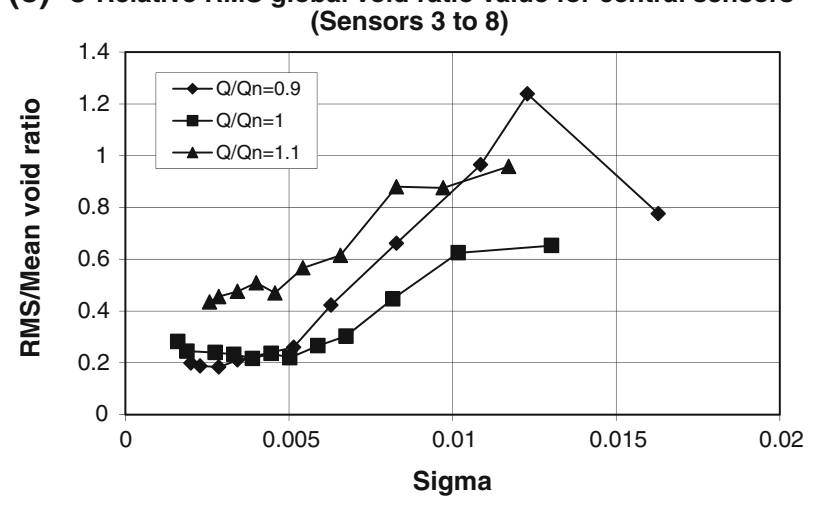

Fig. 9 a Mean void fraction for different $\sigma$ for the three flows for central detectors. $\mathbf{b}$ The standard deviation of the void fraction. $\mathbf{c}$ The ratio of the standard deviation to the mean

higher its incidence with respect to the blade, then the tendency for functioning in extreme conditions concerning the hydrodynamics of blades is higher.

Figures $9 \mathrm{~b}$ and $10 \mathrm{~b}$ illustrate the behavior of the standard deviation of the fluctuations of the void fraction. For the central zone (Fig. 9), we observe a regular increase in fluctuations rate as $\sigma$ decreases. Alone, the flow at $Q / Q_{n}=0.9$ show a singularity under the form of a peak in the proximity of $\sigma=0.0065$. While for the extremities
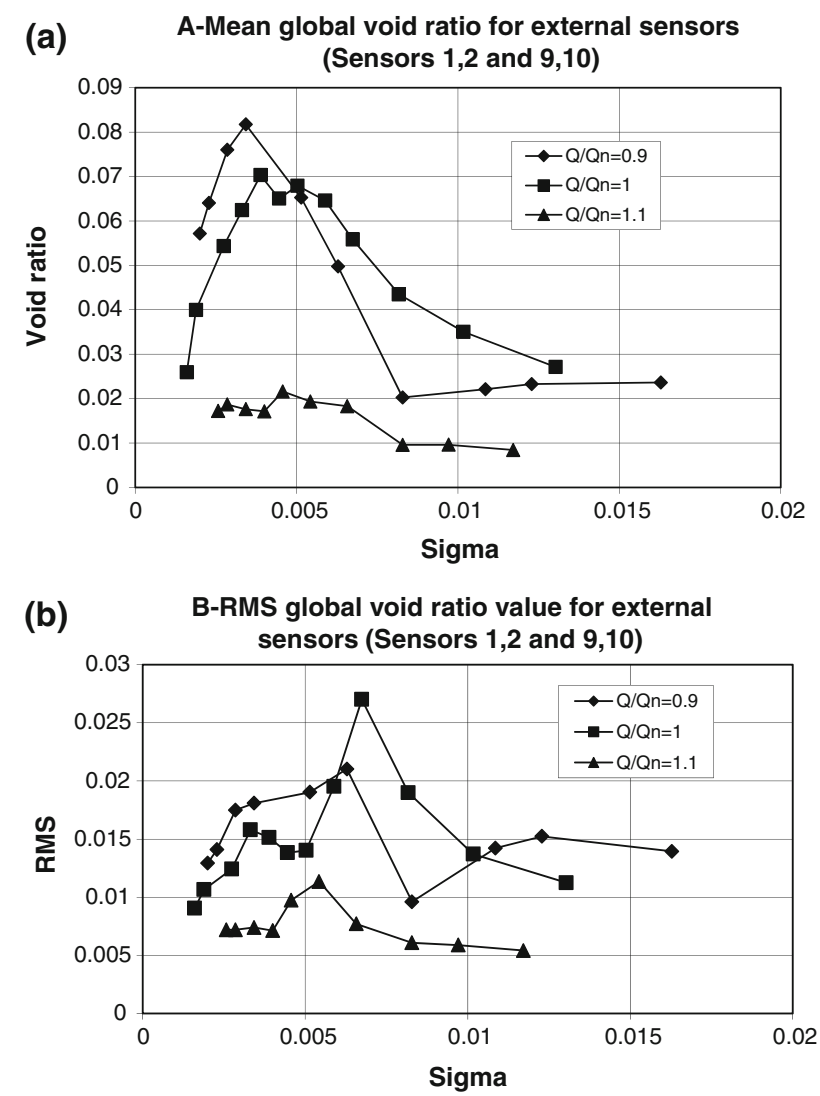

(c) C-Relative RMS global void ratio value for external sensors

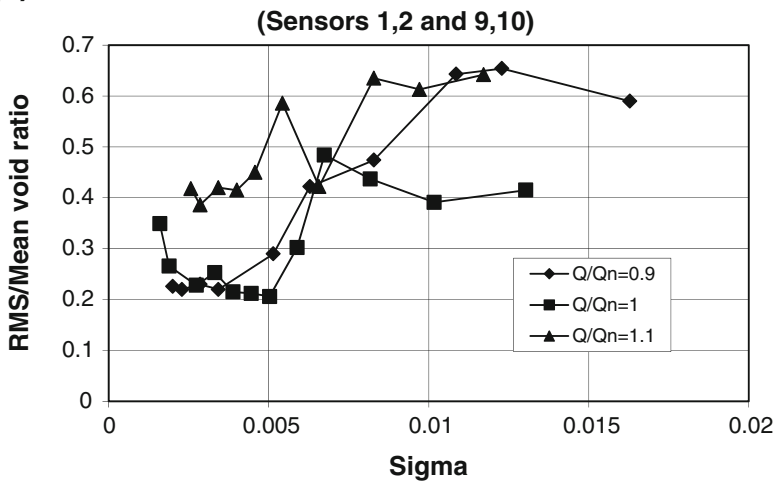

Fig. 10 a Mean void fraction for different $\sigma$ for the three flows for lateral detectors. $\mathbf{b}$ The standard deviation of the void fraction. $\mathbf{c}$ The ratio of the standard deviation to the mean

(Fig. 10), the situation is more complex. Here, we notice a peak of fluctuation at $\sigma=0.0065$ for $Q / Q_{n}=0.9$, while for $Q / Q_{n}=1.0$ the peak is at $\sigma=0.0060$ and for $Q / Q_{n}=1.1$ the peak is at $\sigma=0.0055$. This peak of fluctuation in the external part of the machine could be related to a coupling effect between the tip vortices and some modes related to the blades attached sheets.

In fact this zone corresponds entirely to the appearance of certain hypo-synchronous instability modes $\left(Q / Q_{n}=\right.$ $0.9)$ or hyper synchronous $\left(Q / Q_{n}=1.0\right.$ and $\left.Q / Q_{n}=1.1\right)$ 
Fig. 11 Pressure sensor power spectrum for $4 \sigma$ values $\left(N=4,000 \mathrm{rpm} ; Q / Q_{n}=1\right)$

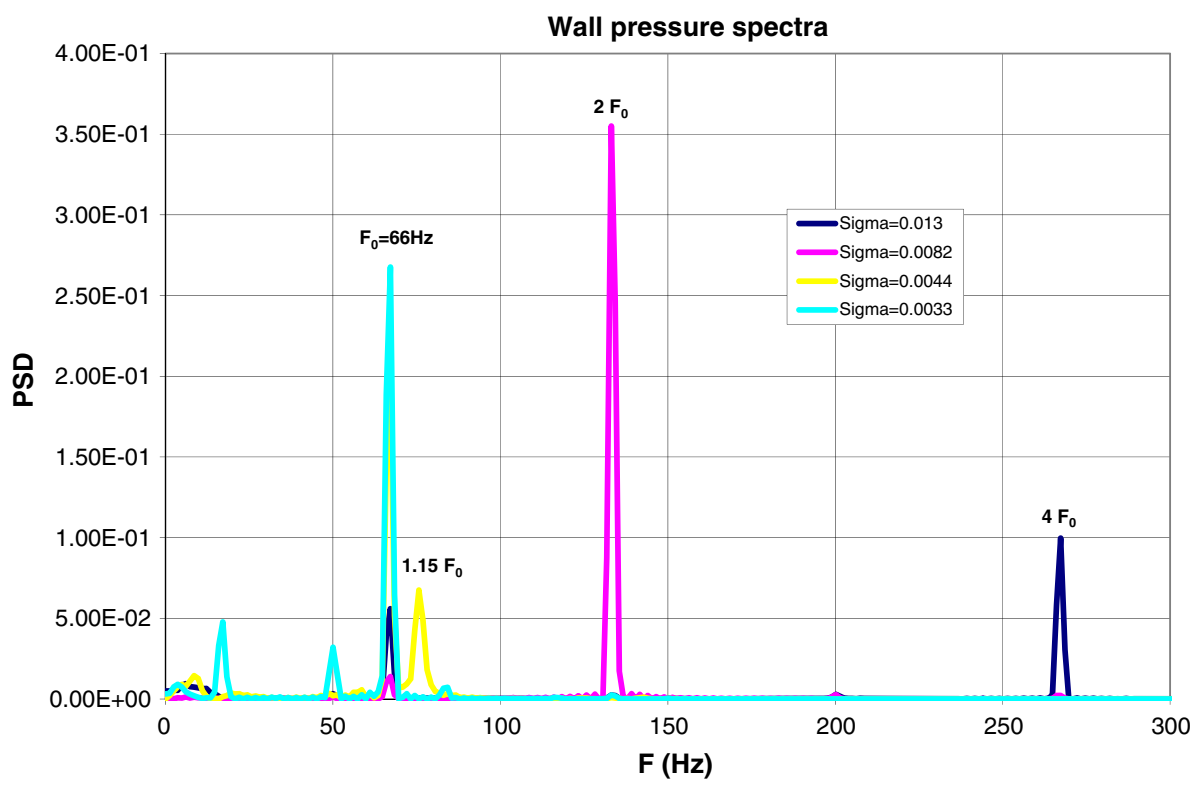

for cavitation pockets attached to the blades. Thus, it is probable that a non-stationary coupling related to the partial installation of this non-stable modes creates these peaks of fluctuations.

Expressing these fluctuations relatively to the mean void fraction as in the Figs. 9c and 10c, we observe a more continuous evolutions except for the external part of the machine (Fig. 10c) for the nominal flow $Q / Q_{n}=1.1$. Whatever the flow rate and the zone of the machine are, the relative level of fluctuation is very high. Therefore, we note that the sheets formed at the beginning of the cavitation cycle turn out the highest relative variations of the void fraction.

\subsection{Spectral analysis}

This paragraph treats the spectral analysis carried out in order to validate the $\mathrm{X}$-ray measurement technique and to obtain information about the cavitation instabilities in the machine. In this paragraph, we are taking into consideration only the case with the nominal flow $Q / Q_{n}=1.0$.

Measured signals are sampled at a frequency of $5 \mathrm{kHz}$ while the analysis is performed on 50,000 points, which corresponds to $10 \mathrm{~s}$ of acquisition.

The principal aim of the present work (concerning spectral analysis) consists in two points:

At first, we will validate the X-ray absorption technique by comparing the void rate spectra obtained by the present $\mathrm{X}$-ray measurements to those obtained classically by means of wall pressure sensor near the impeller housing.

Secondly, we will describe the vapor dynamics inside the impeller by the use of the X-ray absorption spectra.

Figure 11 shows the spectral analysis of a signal provided by a pressure sensor fixed on the housing. These spectra are normalized in a manner that they have the same area, thus permitting to compare them qualitatively independently of the respective energy of the signal that they represent. However, the different intensity of peaks of spectra could not be compared directly with each other in terms of the spectral density of energy.

From these results, we notice well that the spectrum for $\sigma=0.013$ have a peak at the frequency $f_{0}$ and another peak at the frequency $4 f_{0}\left(f_{0}=66.6 \mathrm{~Hz}\right.$ and $\left.4 f_{0}=266.4\right)$. In addition, the spectrum for $\sigma=0.0082$ have a principal peak at $2 f_{0}\left(2 f_{0}=133.2 \mathrm{~Hz}\right)$ associated with a lower amplitude peak at $f_{0}$.

Concerning the mode $3(\sigma=0.0044)$, we have a peak at the frequency $f_{0}$ and a peak at the hyper synchronous frequency $f=76 \mathrm{~Hz}$ which corresponds to the hyper synchronous factor $\alpha=f l f_{0}=1.15$ for the considered $\sigma$. The mode $4(\sigma=0.0033)$ shows a principal peak at $f_{0}$.

Taking into account the results obtained from the pressure fluctuations, we will now compare-at the same functioning points-the spectra of fluctuation of the void fraction measured by the X-ray detector D1 (First detector at higher extremity of the machine). These spectra are represented on Fig. 12 both with the corresponding pressure spectra for confrontation purpose.

The Fig. 12a presents the spectrum of the void fraction compared to that of the pressure sensor for the cavitation mode 1 . At first, we notice that the peak $f_{0}$ is present in the spectrum, and thus, the structures rotating at this frequency are well seen by the X-ray detector. However, in the same spectrum, we observe a peak at $100 \mathrm{~Hz}$ that represents a noisy content. This is related to the fluctuations of the X-ray beam intensity. A treatment method for these variations is presented in previous publications (Hassan et al. 
Fig. 12 Comparison between the spectra of the pressure sensor situated at the housing and the one measured by the detector D1. a $\sigma=0.013$.

b $\sigma=0.0082$
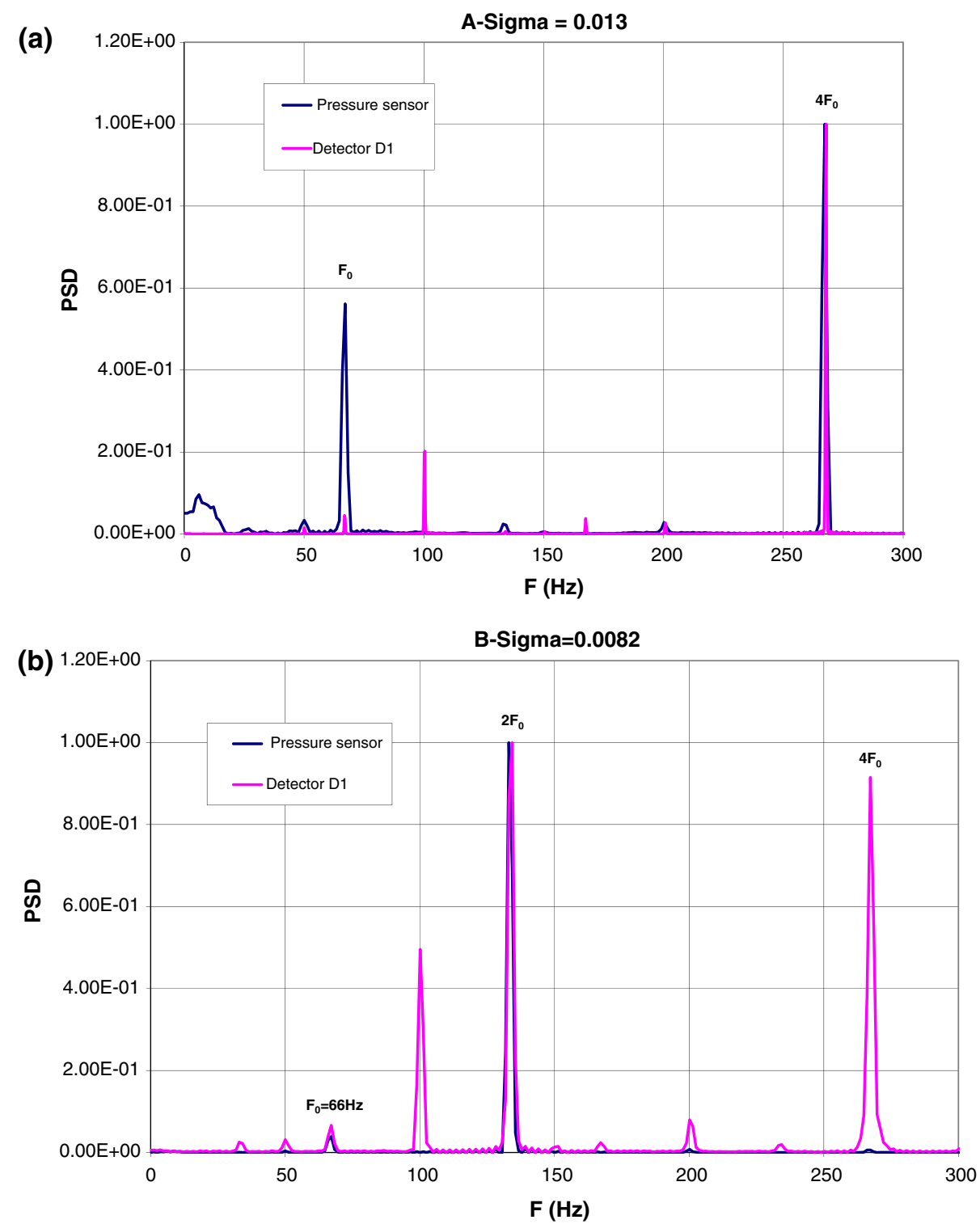

2008; Hassan 2005). At the frequency $4 f_{0}$, we could notice the peak in spectrum, illustrating that the cavitation mode is well detected by the X-ray detector.

The Fig. 12b is equivalent to Fig. 12a, but it is showing the cavitation mode 2 . Here, the two detectors (pressure and $\mathrm{X}$-ray) perceive a peak at the frequency $f_{0}$. Furthermore, the alternating cavitation mode is well seen at the frequency $2 f_{0}$ by the X-ray detector. The spectrum of the void fraction present also a peak at $4 f_{0}$ which is not seen by the pressure sensor. The presence of this peak is normal in regard to the void fraction since the alternating cavitation mode is synchronous, and thus, we should have peaks at $f_{0}, 2 f_{0}$ and $4 f_{0}$ as components of the signal of the void fraction. However, the fluctuation component of the pressure at $4 f_{0}$ is very small thus making its detection less precise with the pressure sensor.
The Fig. 13a treats the case of the cavitation Mode 3, which is a hyper synchronous mode. The two detectors describe well the spectral content of this mode. Moreover, the X-ray detector shows more sensitivity to the component $4 f_{0}$ as compared to the pressure sensor.

The spectral analysis of the last mode of cavitation Mode 4 is presented in the Fig. 13b. The peak corresponding to the frequency $f_{0}$ is well present in the spectrum. Again the $4 f_{0}$ component could be noticed in the spectrum of the void fraction obtained by the X-ray detector while it could not be seen via the pressure sensor.

We can then conclude that for this flow, we denote four principal modes of cavitation in what concerns the blades attached cavitation sheets [see reference (De Bernardi 1996) for a description of the mode dynamics]: 
Fig. 13 Comparison between the spectra of the pressure sensor situated at the housing and that measured by detector D1. a $\sigma=0.0156$.

b $\sigma=0.0116$
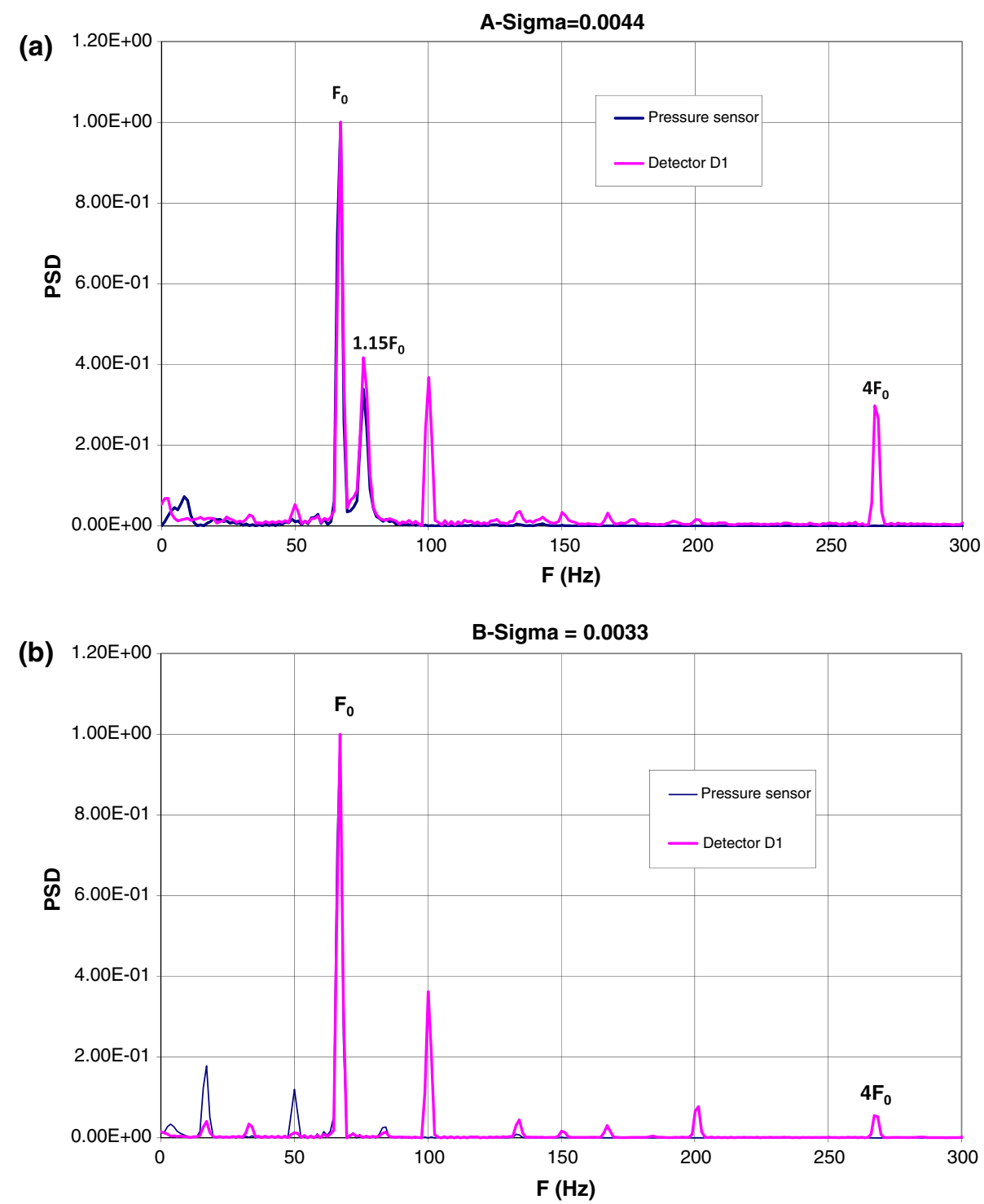

1. Mode 1 this mode corresponds for the range $\sigma=0.013$ and in the neighborhood. In this case, we have cavitation at the extremities of the blades related to the tip vortices and four pockets are attached to the blade body. The spectral content of this mode show principally two frequencies, $f_{0}$, the rotation frequency and, $4 f_{0}$, the frequency of blades.

2. Mode 2 In the range of $\sigma=0.0082$ and in the neighborhood. Here, we have an alternating cavitation consisting of two large sheets and two small ones, all attached to the blades. The phenomenon is synchronous with respect to the rotation frequency, but it generates in addition a frequency $2 f_{0}$ corresponding to the passage of large and small pocket as viewed by a fixed observer.
3. Mode 3 this corresponds to $\sigma=0.0044$ and in the neighborhood. In this case, we have three large sheets and a small one. In addition, this cavitation phenomenon is not synchronous with the rotation frequency of the machine. The cavitation structures rotate slightly more rapidly than the machine in a fixed reference. So here, we are in a hyper synchronous mode generating a frequency of $\alpha f_{0}$, where $\alpha$ varies between 1.1 and 1.5 depending on the value of $\sigma$ considered in the zone where this mode is active.

4. Mode $4 \sigma=0.0033$ and in the neighborhood. This mode corresponds to the end of the cavitation cycle. It is constituted of 4 large sheets attached to the blades, rotating at the same rotation frequency of the machine. 
Fig. 14 Instantaneous picture (visible light) of the inducer's front view experiencing cavitating mode 3
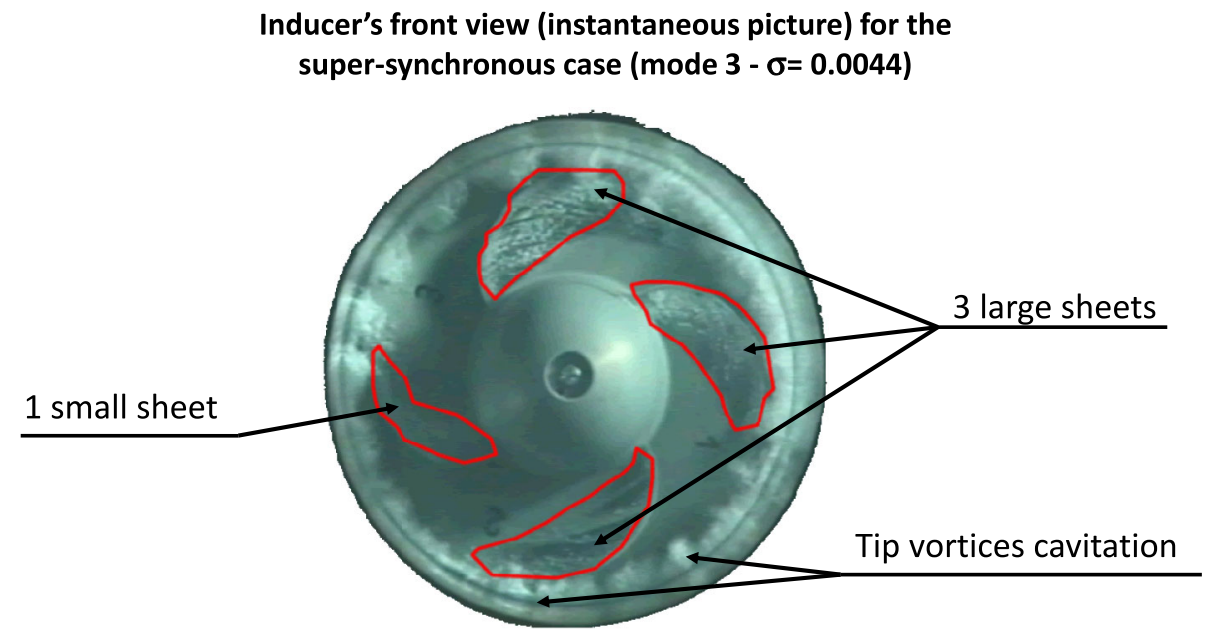

It generates principally a spectral component of frequency $f_{0}$.

In order to help the overall understanding of the flow structuration inside the inducer, we will present an example of the diphasic structure inside the inducer. An instantaneous picture taken in front of the inducer flow for $\sigma=0.0044$ (Mode 3-Hyper synchronous) is displayed on Fig. 14. The vapor structuration is clearly described on this picture in which the three large sheets and the fourth small one attached to the blades are clearly identifiable (Mode 3). Tip vortices cavitation is also visible at the inducer's periphery which explains the higher observed void ratio when using only extremes detectors (D1, D2, D9, D10). This is illustrated on Figs. 5a, 6a, 7a, 8a, 9a and 10a.

\section{Conclusion}

The vapor fraction in the machine was measured despite technical difficulties related to the complex geometric design of the inducer and its high rotation speed. Adequate procedures were developed to treat fluctuations in the measurements due to X-ray beam instabilities.

Important information concerning the amount and the repartition of the vapor in the cavitating inducer has been obtained using X-ray absorption method. These results are original and innovative. They may help the global understanding of the cavitation dynamics in this kind of turbomachine and especially produce important non-stationary data for the numerical simulation of such complex flows.

As a conclusion to this approach, we can consider that the spectral analysis of the instable modes of cavitation could be achieved via the analysis of the void fraction measured by the X-ray detectors. The detection quality of the $\mathrm{X}$-ray detector is superior to that of the pressure sensor in addition it offers the possibility of more deep analysis leading to a deeper comprehension of the cavitation phenomenon in the inducer. However, more information could be obtained via the analysis of the tomographic reconstruction of the repartition of the void fraction in the machine. This task can be achieved using a phase averaging process leading to a $2 \mathrm{D}$ void fraction distribution without instantaneous temporal information. At the opposite, the present work presents a spatially integrated instantaneous analysis.

Acknowledgments Great thanks are addressed to the CNES and to SNECMA motors, the financial supporters of the project.

\section{References}

Bauer D, Chaves H, ARCOUMANIS C (2012) Measurements of void fraction distribution in cavitating pipe flow using $\mathrm{x}$-ray CT. Meas Sci Technol 23(5):055302

Chanteloup D, Bölcs A (2001) PIV investigation of the flow characteristics in 2-leg internal coolant passages of gas turbine airfoils. In: Proceedings of the Euroturbo, European conference on turbomachinery fluid dynamics and thermodynamics. Firenze, Italy. March, 2001

Cheong SK, Liu J, Shu D, Wang J, Powell CF Effects of ambient pressure on dynamics of near-nozzle diesel sprays studied by ultrafast X-radiography. SAE Paper 2004-01-2026

Coulon D (1999a) The Ariane-5 evolution programme: three years after Toulouse. Directorate for Launchers, ESA, Paris

Coulon D (1999b) Vulcain-2 cryogenic engine passes first test with new nozzle extension. Directorate for Launchers, ESA, Paris

Coutier-Delgosha O, Devillers JF, Pichon T, Vabre A, Woo R, Legoupil S (2003) Internal styructure and dynamics of sheet cavitation, ENSTA report

De Bernardi J (1996) Aspects expérimentaux et théoriques des instabilités de cavitation dans les turbopompes de moteurs de fusées. Ph.D. Thesis, Grenoble Institute of Technology

Ebrahimi HB (2002) An overview of computational fluid dynamics for application to advanced propulsion systems. In: 11th AIAA/ AAAF international conference, space planes and hypersonic systems and technologies. AIAA-2002-5130 
Franc JP, Janson E, Morel P, Rebattet C, Riondet M (2001) Visualizations of leading edge cavitation in an inducer at different temperatures. CAV (2001): fourth international symposium on cavitation, June 20-23, 2001, California Institute of Technology, Pasadena, CA USA

Freud N, Duvauchellea P, Létanga JM, Babota D (2006) Fast and robust ray casting algorithms for virtual X-ray imaging. Nucl Instrum Methods Phys Res B Beam Interact Mater At 248(1): $175-180$

Giannadakis E, Gavaises M, Arcoumanis C (2008) Modelling of cavitation in diesel injector nozzles. J Fluid Mech 616:153-193

Han P, Wesser U (1993) Estimating bubble size velocity and void fraction of two phase flow with Compton scattering. FED-Vol. 165, Gas fluid flows 1993 ASME 1993

Hassan W (2005) Développement d'un système tomographique pour la détermination expérimentale du volume de vapeur présent au sein des turbopompes spatiales. Ph.D. Thesis, Grenoble Institute of Technology

Hassan W, Barre S, Legoupil S, Rebattet C (2005) Dynamic vapor fraction measurement in Ariane 5 inducer by x-rays. In: Proceedings of FEDSM2005, ASME fluids engineering division summer meeting and exhibition, Houston, TX, USA, 19-23 June 2005

Hassan W, Chambellan D, Legoupil S, Barre S (2005) Dynamic localization of vapor fraction in Ariane 5 inducer by $\mathrm{X}$-ray tomography. Nuclear science symposium and medical imaging conference. Wyndham El Conquistador Resort, Puerto Rico, 23-29 Oct 2005

Hassan W, Legoupil S, Chambellan D, Barre S (2008) Dynamic localization of vapor fraction in turbo pump inducers by X-ray tomography. IEEE Trans Nucl Sci 55(1):656-661

Heindel TJ (2011) A review of X-ray flow visualization with applications to multiphase flows. J Fluids Eng 133(7):074001

Kastengren AL, Powell CF, Cheong SK, Wang Y, Im KS, Liu Xin, Wang J (2007a) Determination of diesel spray axial velocity using X-ray radiography. SAE Paper 2007-01-0666

Kastengren AL, Powell CF, Wang Y-J, Wang J (2007b) Study of diesel jet variability using single-shot $\mathrm{X}$-ray radiography. In: Proceedings of the ASME internal combustion engine division, Charleston, USA, October 2007

Lecoffre Y (1994) La cavitation, traqueurs de bulles. Edition HERMES Paris

Leick P, Reidel T, Bittlinger G, Powell CF, Kastengren AL, Wang J (2007) X-ray measurements of the mass distribution in the dense primary break-up region of the spray from a standard multi-hole common-rail diesel injection system. In: Proceedings of the 21st ILASS-Europe meeting

Mäkiharju SA, Gabillet C, Paik B-G et al (2013) Time-resolved twodimensional X-ray densitometry of a two-phase flow downstream of a ventilated cavity. Exp Fluids 54(7):1-21

Powell CF, Yue Y, Cheong S-K, Narayanan S, Cuenca R, Ciatti SA, Shu D, Wang J Effects of ambient pressure on fuel sprays as measured using X-ray absorption. In: Proceedings of the 16th ILASS annual conference, Monterey, CA, May 2003

Ramirez AI, Som S, Aggarwal SK, Kastengren AL, El-Hannouny EM, Longman DE, Powell CF (2009) Quantitative X-ray measurements of high-pressure fuel sprays from a production heavy duty diesel injector. Exp Fluids 47:119-134. doi:10.1007/ s00348-009-0643-4

Saarenrinne P, Honkanen M, Parssinen T, Eloranta H (2004) Digital imaging and PIV methods in multiphase flows. Institute of Energy and Process Engineering, Tempere 2004

Shimizu S, Ihara A, Okada M, Sakurai M (2001) In: Damage due to spot cavitation on hemispherical cylindrical body comparison between isolated cavity and parallel cavities. CAV 2001: fourth international symposium on cavitation, June 20-23, 2001, California Institute of Technology, Pasadena, CA USA

Stutz B, Legoupil S (2003) X-ray measurements within unsteady cavitation. Exp Fluids 35:130

Stutz B, Legoupil S, Woo R (2002) Measurements within cloud cavitation by means of X-ray attenuation device. In: Proceedings of ASME FEDSM'02, Montreal, Quebec, Canada, July 14-18, 2002

Tola F (1996) Logiciels d'aide à la conception et à l'interprétation de mesures basées sur la détection d'un rayonnement X. DAMRI/ SAR/S/96-123/T41, 1996, Commisariat à l'energie atom-ique, Grenoble, France

Vabre A, Gmar M, Lazaro D, Legoupil S, Coutier-Delghosa O, Dazin A, Lee WK, Fezzaa K (2009) Synchrotron ultra-fast X-ray imaging of a cavitating flow in a Venturi profile. Nucl Instrum Methods Phys Res Accel Spectrom Detect Assoc Equip 607(1):215-217

Yue Y, Powell CF, Poola R, Wang J, Schaller J (2001) Quantitative measurements of diesel fuel spray characteristics in the nearnozzle region using X-ray absorption. Atomization Sprays 11:471-490 